\title{
TRABALHO E EDUCAÇÃO: O CURRÍCULO DA REDE ESTADUAL PAULISTA NO CONTEXTO DA REESTRUTURAÇÃO PRODUTIVA DO CAPITAL
}

\author{
Victor Hugo Junqueira ${ }^{1}$ \\ Maria Cristina dos Santos Bezerra ${ }^{2}$
}

\section{RESUMO}

O objetivo deste artigo é discutir as relações entre trabalho e educação no contexto da reestruturação produtiva do capital, tendo como pressupostos teóricos a abordagem materialista e histórica do desenvolvimento capitalista. Nesse sentido, considerando o atual processo de reestruturação produtiva do capital e os seus múltiplos efeitos sobre o mundo do trabalho o artigo enfoca as contradições e ideologias do Currículo do Estado de São Paulo ao definir como prioridade o contexto do trabalho para o Ensino Médio. Os resultados evidenciam que a educação colocada a serviço do capital e dirigida pelas políticas neoliberais não tem significado um aprendizado efetivo, uma vez que é da própria lógica do capitalismo contemporâneo, a exploração de uma grande massa de mão-de-obra adestrada, mas pouco qualificada. Por outro lado, o Currículo da rede estadual paulista, calcado nos fundamentos da pedagogia do aprender a aprender contribui para alimentar a ilusão de uma sociedade do conhecimento que mascara os reais processos de alienação e exploração do trabalhador, submetido à precarização e a exclusão cada vez mais presente no mundo do trabalho.

Palavras-Chave: Trabalho; Educação; Currículo Paulista; Sociedade do Conhecimento

\section{WORK AND EDUCATION: CURRICULUM OF SÃO PAULO STATE NETWORK IN THE CONTEXT OF PRODUCTIVE CAPITAL RESTRUCTURING}

\begin{abstract}
The purpose of this article is to discuss the relationship between work and education in the context of the restructuring of the productive capital, having as theoretical and historical materialist approach of capitalist development. In this sense, considering the current restructuring process of the capital and its multiple effects on the labor the article focuses on the contradictions and ideologies Curriculum of São Paulo to set as a priority the context of work for Secondary Education. The results show that education placed at the service of capital and directed by neoliberal policies has meant an effective learning as it is the very logic of contemporary capitalism, the exploitation of a large mass of skilled manpower adestrada but little qualified. On the other hand, the curriculum of the state of São Paulo, based on the fundamentals of learning to learn the pedagogy contributes to foster the illusion of a knowledge society that masks the actual processes of alienation and exploitation of the worker, subject to exclusion and precariousness increasingly present in the working world
\end{abstract}

Keywords: Work, Education, Curriculum Paulista, Knowledge Society

\section{$O$ ponto de partida: os fundamentos do trabalho na abordagem marxista.}

Os fundamentos materialistas e históricos da análise do real expostos por Marx e Engels em "A ideologia Alemã" (2007) partem do pressuposto de que para fazer história, os indivíduos devem se achar em condições de produzir a sua existência material. As formas como os seres humanos produzem sua existência depende dos objetos retirados 
diretamente da natureza e daqueles produzidos pelos próprios indivíduos para atender as suas necessidades. Neste processo, denominado Trabalho o homem não produz apenas a sua existência física, mas a sua existência humana.

Marx (1996) explica que, a princípio, o trabalho é um processo entre o homem e a natureza, no qual ele media, controla e modifica a natureza externa, ao passo que transforma a sua própria natureza, enquanto os animais só podem utilizar a "natureza e modificá-la pelo mero fato de sua presença nela. $\mathrm{O}$ homem, ao contrário, modifica a natureza e a obriga a servir-lhe, domina-a" (ENGELS, 2004, p. 28). A diferença entre os homens e os animais reside, portanto, no trabalho pré-idealizado e intencionado que os homens realizam para subordinar a natureza a sua existência.

Ao dissertar "Sobre o papel do trabalho na transformação do macaco em homem", Engels (2004, p. 13) é categórico ao afirmar que o trabalho "é condição básica e fundamental de toda vida humana". É no trabalho que está a humanização do homem, a essência do homem é o trabalho, produzida pelos próprios homens na produção de sua existência (SAVIANI, 2007).

Em síntese, o processo de trabalho é "a atividade orientada a um fim para produzir valores de uso, apropriação do natural para satisfazer as necessidades humanas, condição universal do metabolismo entre o homem e a natureza, condição natural eterna da vida humana (MARX, 1996, p. 303).

No processo de desenvolvimento histórico das formas de domínio e subordinação da natureza, pelo homem, para a satisfação de suas necessidades, os homens passam a contrair determinadas relações entre si que tornam a existência humana, uma existência social.

Desse modo,

A produção da vida, tanto da própria vida no trabalho quanto da vida estranha na procriação, parece já se mostrar desde logo na condição de relação dupla - de um lado, como relação natural, e de outro, como relação social -, social no sentido de que por ela se entende a cooperação de diversos indivíduos, quaisquer que sejam as condições, de qualquer modo e para qualquer fim. (MARX; ENGELS, 2007, p.52)

Inicialmente a produção da vida social esteve baseada em relações de produção fundadas na propriedade comunal das terras, apropriação coletiva do resultado do trabalho e da inexistência de divisão entre classes sociais (comunismo primitivo). Contudo, em determinado momento

numa fase bastante primitiva do desenvolvimento da produção, a força de trabalho do homem se tornou apta para produzir consideravelmente mais do que era preciso para a manutenção do produtor, e [...] essa fase de desenvolvimento é, no essencial, a mesma em que nasceram a divisão do trabalho e a troca entre indivíduos. Não se demorou muito a descobrir a grande "verdade" de que também o homem podia servir de mercadoria, de que a força de trabalho do homem podia chegar a ser objeto de troca e consumo, desde que o homem se transformasse em escravo (ENGELS, 1984 p.198).

A complexificação das relações sociais de produção no seio da sociedade primitiva e a produção do excedente pela potencial combinação de diferentes trabalhos conduziram a desagregação da própria sociedade primitiva, instituindo a divisão do trabalho, o domínio 
privado da terra e a divisão da sociedade em duas classes sociais distintas e opostas: proprietários e não-proprietários, dominantes e dominados.

O domínio da propriedade privada por uma classe social (proprietários) impede a classe dos não-proprietários o acesso direto as condições materiais para prover a sua existência e, o trabalhador, é separado dos meios, dos instrumentos e do produto do seu trabalho. O trabalho, assim, adquire um duplo sentido na sociedade de classes, para os nãoproprietários restam-lhes apenas a sua força de trabalho que deve fornecer aos proprietários em troca de manter-se vivo. Já para os proprietários, o domínio dos meios de produção possibilita viver da exploração do trabalho alheio.

Nos diferentes estágios da produção, a divisão social do trabalho, as diferentes formas de propriedade condicionam as relações entre os indivíduos no que tange ao material, ao instrumento e ao produto do trabalho (MARX, 2007). A escravidão na antiguidade, a servidão no feudalismo e o trabalho assalariado no capitalismo são expressões, ainda que diferenciadas, do mesmo processo de cisão e oposição entre exploradores e explorados.

No capitalismo, o trabalho é colocado a serviço do capital, para a valorização do capital, por meio da exploração incessante da mais valia. $\mathrm{O}$ trabalhador livre, desprovido de todos os meios de produção e possuidor apenas de sua força de trabalho, sujeita-se, portanto, ao capital que o transforma em mercadoria.

Marx (1996, p. 304) observa que no curso de desenvolvimento capitalista ocorrem dois fenômenos peculiares, primeiro "o trabalhador trabalha sob controle do capitalista a quem pertence seu trabalho"; e segundo, "o produto é propriedade do capitalista, e não do produtor direto, do trabalhador".

Neste processo o ato da produção dentro do trabalho e o produto do trabalho tornam-se estranhos ao trabalhador, torna-se trabalho alienado. Conforme Marx (1996, p. 162) "o trabalho é exterior ao trabalhador, quer dizer não pertence à sua natureza, portanto, ele não se afirma no trabalho, mas nega-se a si mesmo [...]. Não constitui satisfação das necessidades, mas apenas um meio de satisfazer outras necessidades".

A separação do homem do seu trabalho, enquanto fonte criadora da sua existência, a separação do produto do trabalho no processo de sujeição da exploração capitalista, aliena o homem de si mesmo, aliena a sua natureza e a sua vida genérica, e, em consequência, aliena-se na relação com outros homens. Este processo é tão mais intenso, quanto mais se desenvolve o processo de produção capitalista e a divisão do trabalho, "o trabalhador torna-se uma mercadoria tanto mais barata, quanto maior número de bens produz. Com a valorização do mundo das coisas aumenta em proporção direta a desvalorização do mundo dos homens" (MARX, 1989, p. 159).

Marx, no livro I de "O Capital", expõe como no processo histórico de desenvolvimento capitalista, o trabalho torna-se alienado e desvalorizado. Desde a cooperação, ponto de partida da produção capitalista, ao combinar o emprego simultâneo de grande número de trabalhadores no mesmo local, criando uma nova força produtiva - a força social -, passando pela divisão do trabalho na manufatura, com a formação do trabalhador parcial como parte da engrenagem do sistema produtivo, o trabalhador perde o domínio do processo de produção, ao passo que o seu saber produtivo acumulado passa a ser apropriado pelo capitalista.

Entretanto, é com a maquinaria que vem o golpe de misericórdia. O trabalhador já desvalorizado e alienado, torna-se um simples apêndice da máquina, despojado de qualquer saber e capacidade criadora, sujeito ao ritmo da máquina imposto pelo capitalista. Marx (1996, p. 55) sintetiza: na "manufatura, os trabalhadores constituem membros de um 
mecanismo vivo. Na fábrica, há um mecanismo morto, independente deles, ao qual são incorporados como um apêndice vivo".

Além disso, Marx (1996) aponta como o ingresso da maquinaria alterou profundamente a sociedade capitalista. Ao tornar desnecessária a força muscular o capitalismo introduziu mulheres e crianças no mercado de trabalho sob comando do capital, desvalorizando ainda mais a força de trabalho individual. Outro efeito foi a ampliação da exploração dos trabalhadores, a princípio pelo prolongamento da jornada de trabalho, entretanto, o limite físico dos trabalhadores e as revoltas desencadeadas, obrigou os capitalistas a substituírem o prolongamento da jornada de trabalho pela intensificação da jornada de trabalho, assim, "a máquina, na mão do capitalista, transforma-se no meio objetivo e sistematicamente aplicado para espremer mais trabalho no mesmo espaço de tempo" (MARX, 1996, p.44).

Sem pretender realizar uma exposição exaustiva sobre as transformações do trabalho na sociedade capitalista, é preciso destacar que na sociedade capitalista, o trabalho, categoria ontológica e essência humana, transforma-se em trabalho alienado, escravo a serviço da valorização do capital.

\section{Trabalho e Educação: princípios da educação escolar sob domínio do capital.}

Partindo da realidade material e concreta do trabalho, tomando-o como categoria central para análise do real é que pensamos a relação com a educação. Aqui, retomamos e reafirmamos a tese de Lombardi (2010) segundo o qual,

a educação (e o ensino) é determinada, em última instância, pelo modo de produção da vida material; isto é, pela forma como os homens produzem sua vida material, bem como as relações aí implicadas, quais sejam, as relações de produção e as forças produtivas são fundamentais para apreender o modo como os homens vivem, pensam e transmitem as idéias e os conhecimentos que têm sobre a vida e sobre a realidade natural e social.

Os trabalhos de Ponce (2005) e de Saviani (2007) apresentam a relação entre trabalho e educação nos diferentes modos de produção (primitivo, escravista, feudal e capitalista), sustentando a tese de que o surgimento da educação escolar como forma dominante de educação é produto da sociedade de classes, que invariavelmente, conduz a uma divisão na educação para proprietários e não-proprietários dos meios de produção.

$\mathrm{Na}$ sociedade capitalista as relações de exploração baseadas no direito natural, são suprimidas pelo direito contratual, na qual colocam em relação de igualdade trabalhadores e capitalistas como livres proprietários para negociar via mercado. Os primeiros livres de todos os meios de existência e proprietários unicamente de sua força de trabalho, devem vendê-la em troca de um salário ao segundo, proprietários dos meios de produção.

Neste contexto, a generalização da escola torna-se uma exigência da burguesia como forma de garantir a sociedade contratual e a socialização dos indivíduos no convívio da sociedade moderna (SAVIANI, 2007). Além disso, a educação para a classe trabalhadora prescindiu de um segundo componente, a amenização da degradação moral a que eram submetidos os trabalhadores pela simplificação do trabalho. Ao analisar este processo na manufatura, Marx (1996, p.416) apresenta a solução burguesa: "A fim de evitar a degeneração completa da massa do povo, originada pela divisão do trabalho, A. Smith recomenda o ensino popular pelo Estado, embora em doses prudentemente homeopáticas" 
Contudo, como já observamos, a maquinaria simplifica ainda mais as funções do trabalhador, ampliando a sua degradação moral e intelectual. Nestas condições:

\begin{abstract}
a devastação intelectual, artificialmente produzida pela transformação de pessoas imaturas em meras máquinas de produção de mais-valia - que deve ser bem distinguida daquela ignorância natural que deixa o espírito ocioso sem estragar a sua capacidade de desenvolvimento, a sua própria fecundidade natural -, obrigou, finalmente, até mesmo o Parlamento inglês a fazer do ensino primário a condição legal para o uso "produtivo" de crianças com menos de 14 anos em todas as indústrias sujeitas às leis fabris (MARX, 1996, p. 33).
\end{abstract}

Não é fortuito, portanto, que a generalização da educação escolar torne-se uma própria exigência da burguesia nos países nos quais a produção industrial e a urbanização avançam.

Por outro lado, a divisão do trabalho intelectual e manual e as múltiplas segmentações nos trabalhos produtivos, exigem diferenciações na formação dos trabalhadores conforme as necessidades históricas do capital. A citação de Lombardi (2010, p. 266) é conclusiva "numa sociedade com classes e frações de classes diferenciadas, também a educação era (é) adequada a essa estrutura e organização econômica e social, com tantas e quantas educações quantas as classes e frações de classes a que se destinam".

Nesta perspectiva, na sociedade de classes capitalista, na qual a transformação da humanidade trabalhadora como instrumento do capital é um movimento incessante e interminável (BRAVERMAN, 1987), mas que não o faz como um bloco monolítico que arrasta a tudo e todos permanentemente, mas que se move com fissuras, obstáculos e contradições, a educação (para os capitalistas) cumpre um papel importante ao adestrar, conformar e quebrar as resistências dos trabalhadores de acordo com as necessidades de produção, valorização e reprodução do capital, que dado ao seu processo contraditório é mutável em suas morfologias ao longo da história.

\title{
A reestruturação produtiva do capital e a complexificação das relações de trabalho.
}

O capitalismo move-se por processos de reestruturações produtivas como mecanismo de superar as suas próprias contradições e crises estruturais de acumulação e reprodução. Desde a cooperação manufatureira, estágio inicial de desenvolvimento capitalista, passando pela maquinaria e grande indústria ao chegar aos estágios mais avançados de desenvolvimento da produção capitalista, as alterações produtivas impactaram não apenas na organização do trabalho, mas na própria constituição do ser social e da sua vida em sociedade.

Kuenzer (2007) partindo da análise do texto Americanismo e Fordismo de Gramsci (1978) explica que a cada nova relação de produção e formas de organização do trabalho são demandados, concebidos e veiculados novos modos de vida, comportamentos, atitudes e valores que conformem o trabalhador na sua alienação e produza um novo homem com atitudes e comportamentos adequados aos processos de valorização.

No final do século XIX e ao longo do século XX a reestruturação do capitalismo foi marcada pelas inovações fordista-taylorista que dominaram os processos industriais. Alves (2007) explica que a introdução destes novos modelos produtivos não foi uniforme, mas, lenta, desigual e combinada, atingindo de forma diferenciada países e regiões, setores e empresas da indústria ou de serviço ao longo de todo o século XX. 
A consolidação do domínio fordista-taylorista no mundo prescindiu de uma complexa relação capital - trabalho - Estado que possibilitou por um lado, expansão capitalista pelo mundo (no imperialismo e no pós-guerra) difundindo o consumo de mercadorias industrializadas, consequentemente aumentando a produção, e por outro lado, quebrou as resistências dos trabalhadores ao aumento da produtividade, seja pela organização e gerência científica do trabalho (BRAVERMAN, 1987) ou pelo adestramento e consentimento da classe trabalhadora a exploração capitalista.

O modelo fordista-taylorista ou acumulação rígida teve como pilares a racionalização da produção, intensiva divisão e repetição de tarefas (conforme proposto por Taylor) para produção padronizada e em massa. A organização e gerência científica do trabalho sobre o fordismo-taylorismo intensificou ao máximo a fragmentação do trabalho no chão da fábrica, despojando o trabalhador de qualquer saber e servindo ao ritmo cada vez mais veloz das máquinas.

Esta organização produtiva do trabalho na qual impera a divisão entre trabalho intelectual e manual, especialização de tarefas e fragmentação do trabalhador a organização escolar sedimentou a dualidade estrutural (Kuenzer, 2007) que opõe claramente a educação para a burguesia e a educação para os trabalhadores, destinando-se aos últimos, doses homeopáticas de conhecimento, necessários a integração produtiva e consentimento civilizatório ao processo de exploração capitalista.

Paralelamente, expandiu-se a oferta de cursos profissionalizantes destinados aos trabalhadores, nos quais a "primazia do saber tácito sobre o conhecimento científico, da prática sobre a teoria, da parte sobre a totalidade" (KUENZER, 2007, p.1157) adequava-se aos interesses particulares do capitalismo, não representando uma democratização do conhecimento, mas o aprofundamento da divisão de classes (KUENZER, 2007).

Todavia, a partir do fim década de 1970 o modelo fordista-taylorista começou a apresentar sinais de esgotamento, a crise inflacionária, a crise do petróleo, a ampliação concorrência inter-capitalistas diante do processo de mundialização do capital e a necessidade de controlar o movimento operário e a luta de classes, são expressões combinadas da crise estrutural do capital que levaram a um novo processo de reestruturação produtiva do capital, denominado Toyotismo. (ALVES, 2007; ANTUNES, 2011, HARVEY, 1992).

Esta reestruturação capitalista orientada para melhor aproveitamento de matériasprimas, das fontes energéticas e da força de trabalho, teve entre suas estratégias, de um lado, a mudança técnica de produção a partir da aplicação de uma forte política de inovações científicas e tecnológicas, centradas na informática, na microeletrônica, na robótica; e do outro, em novas formas de racionalização da produção e aproveitamento da força de trabalho, baseada em formas flexíveis de acumulação e captura da subjetividade do trabalhador modificaram as formas de produção industrial, as relações de trabalho, a organização espaço-tempo e implicou em uma maior fluidez internacional de capitais. (HARVEY, 1992; SANTOS, 2008).

Nesse sentido, o toyotismo a partir da década de 1970, representou um novo estágio de desenvolvimento capitalista, mais adequado ao processo de mundialização do capital, mas conforme Alves (2007, p. 161):

não se constitui como 'modelo puro' de organização da produção capitalista. Pelo contrário, em seu desenvolvimento complexo, tende a articular-se (e mesclar-se) com formas pretéritas de racionalização do trabalho (como o fordismo-taylorismo), momentos não-predominantes do novo regime de acumulação flexível. 
Assim, fundado na lógica produtivista da indústria capitalista, da reprodução de capital, por meio da ampliação da produtividade do trabalhador e a subtração da maisvalia, com resquícios de formas pretéritas de organização do trabalho, o toyotismo cria uma nova racionalização da produção que acelera a reprodução do capital, valendo-se de uma produção enxuta e flexível. A produção diversificada orientada pela demanda (Just-intime), a automação dos processos industriais, o controle de estoques (Kan-bam), a implantação de Círculos de Controle de Qualidade (CCQs), a integração vertical das diferentes etapas de produção, reduziram drasticamente o ciclo de reprodução do capital.

Esta forma de acumulação flexível teve conseqüências profundas na organização e nas relações de trabalho, a exploração extensiva do trabalho fordista-taylorista, cede lugar à exploração intensiva da força de trabalho, a partir da "captura" da subjetividade do trabalhador para a ampliação da produtividade e o consentimento a exploração capitalista.

Segundo Alves (2007, p.186) "não é apenas o "fazer" e o "saber" operário que são capturados pela lógica do capital, mas sua disposição intelectual-afetiva que é mobilizada para cooperar com a lógica da valorização". Com efeito, o espírito da racionalização capitalista no local de trabalho, "tende a agir sobre o trabalho organizado e sua subjetividade, precarizando-a e buscando subsumi-la aos interesses da reprodução do capital como sistema sócio-metabólico" ALVES (2007, p. 189)

Antunes (2011, p.47) destaca, também, a múltipla processualidade que caracteriza o universo do mundo do trabalho, sob o regime de acumulação flexível,

[...] de um lado verificou-se a desproletarização do trabalho industrial, fabril, nos países de capitalismo avançado, com maior ou menor repercussão em áreas industrializadas do Terceiro Mundo. Em outras palavras, houve uma diminuição da classe operária industrial tradicional. Mas, paralelamente, efetivou-se uma expressiva expansão do trabalho assalariado, a partir da enorme ampliação do assalariamento no setor de serviços; verificou-se uma significativa heterogeneização do trabalho, expressa também através da incorporação do contingente feminino no mundo operário; vivencia-se também uma subproletarização intensificada, presente na expansão do trabalho parcial, temporário.

Dessa forma, a reestruturação produtiva fragmentou, heterogeneizou e complexificou ainda mais a classe trabalhadora (ANTUNES, 2000). Ao passo, que ampliou a exigência da qualificação em alguns setores, na busca incessante da captura da subjetividade ao processo de valorização do capital, por outro lado, produziu uma massa de trabalhadores, desqualificados, precarizados, que competem pelas parcas vagas no mercado formal e informal de trabalho, igualmente necessários a reprodução do capital.

Segundo Antunes (2011, p. 43)

Criou-se, de um lado, em escala minoritária, o trabalhador "polivalente e multifuncional" da era informacional, capaz de operar com máquinas com controle numérico e de, por vezes, exercitar com mais intensidade sua dimensão mais intelectual. E, de outro lado, há uma massa de trabalhadores precarizadados, sem qualificação, que hoje está presenciando as formas de part-time, emprego temporário, parcial, ou então vivenciando o desemprego estrutural.

Com o desenvolvimento e descentralização da produção capitalista em escala global, estas relações de trabalho tendem a ser difundidas por todos os espaços, não como um movimento linear e sincrônico, mas desigualmente implantada sobre a base pretérita, 
que ao passo que globaliza a produção, sujeita os trabalhadores de diferentes regiões do mundo a diferentes formas de exploração, tão quão necessárias forem à continuidade da reprodução de capital.

\section{O mercado de trabalho sob o regime de acumulação flexível: breves apontamentos sobre a realidade brasileira e paulista.}

O processo de reestruturação toyotista do capital e o conjunto de políticas neoliberais que o sustentam, tiveram inicio no Brasil a partir da década de 1990, abrindo as portas do país ao domínio do capital financeiro internacional, como forma de inserção na nova ordem globalizada, competitiva e excludente.

Neste contexto, no qual os espaços nacionais passam a ser regidos por lógicas exógenas (SANTOS, 2008) o processo de competitividade e flexibilidade da produção toyotista, se instalou no país, modernizando e aumentando a produtividade industrial e agrícola. Além disso, a abertura comercial do Brasil e o ingresso de capitais internacionais no país forçaram a implantação da mesma dinâmica de aceleração de reprodução do capital dos países capitalistas centrais.

Este processo exigiu a reordenação do Estado brasileiro na coordenação de políticas econômicas que favorecem a reprodução do capital, ao mesmo tempo, em que garante a ordem social necessária à manutenção do capitalismo, seja no controle ideológico e adestramento da classe trabalhadora ou na própria conformação subjetiva do indivíduo aos processos de reprodução capitalista.

Harvey (2005) destaca que na economia capitalista o Estado deve assumir as seguintes funções: a privatização dos bens e serviços públicos, regulação da competição, regulação da exploração do trabalho, provimento de "bens públicos" e infra-estruturas sociais e físicas ao capital e administração de crises e ação contra a tendência a queda da margem de lucro.

Seguindo estas diretrizes a reforma do Estado brasileiro promovida pelo governo Fernando Henrique Cardoso (1994-2002) e continuada no governo Lula (2003-2010) garantiu ao capitalismo internacional um terreno fértil para sua reprodução, seja pelas políticas estruturantes de privatização, mas também, pela mudança no papel das instituições e dos serviços públicos.

$\mathrm{Na}$ esteira destes processos, o mercado de trabalho foi impactado, por um lado, pela exigência de novas qualificações para os processos industriais cada vez mais especializados tecnicamente e territorialmente - a intelectualização do trabalho manual-e por outro, pelo crescente processo de informalidade, subcontratações e terceirização dos serviços (ANTUNES, 2011).

Considerando a década de 1990, período denominado por Antunes (2004) como a desertificação neoliberal, os ajustes estruturais da economia seguidos por um baixo crescimento econômico, precarizaram as condições de trabalho em todo o país, seja pelos seguidos processos de automação industrial, ou pela redução das garantias empregatícias cujos efeitos mensuráveis, entre outros, foram a ampliação do desemprego e o crescimento das taxas de informalidade no país. (ANTUNES 2004, 2011; ALVES, 2012; POCHMANN, 1999)

Os dados do IBGE mostram a evolução na taxa de desemprego e informalidade ${ }^{3}$ entre os anos de 1992 e $1999^{4}$ para o Brasil e para o Estado de São Paulo.

Tabela 1 - Evolução da taxa de desemprego e informalidade entre 1992 e 1999 no Brasil e no Estado de São Paulo (\%) 


\begin{tabular}{ccccc}
\hline Período & $\begin{array}{c}\text { Taxa de } \\
\text { Desemprego }(\%) \\
\text { Brasil }\end{array}$ & $\begin{array}{c}\text { Taxa de } \\
\text { Desemprego } \\
(\boldsymbol{\%}) \text { São Paulo }\end{array}$ & $\begin{array}{c}\text { Taxa de } \\
\text { Informalidade } \\
(\%) \text { Brasil }\end{array}$ & $\begin{array}{c}\text { Taxa de } \\
\text { Informalidade } \\
(\%) \text { em SP }\end{array}$ \\
\hline 1992 & 7,2 & 8,8 & 54,3 & 38,6 \\
1993 & 6,8 & 7,8 & 55,0 & 40,1 \\
1995 & 6,7 & 8,0 & 55,2 & 41,9 \\
1996 & 7,6 & 9,1 & 54,9 & 42,8 \\
1997 & 8,5 & 10,6 & 55,2 & 42,7 \\
1998 & 9,7 & 12,8 & 55,6 & 43,7 \\
1999 & 10,4 & 12,9 & 56,2 & 44,4
\end{tabular}

Fonte: IBGE/ IPEAdata. Org. Victor Hugo Junqueira

No período considerado, a partir de 1995 o ritmo do crescimento do desemprego no Brasil foi gradativo. Já a taxa de informalidade, mesmo apresentando flutuações, mantevese em um patamar superior a 50\%, atingindo seu valor máximo em 1999. O Estado de São Paulo acompanhou os mesmos processos nacionais, com pequenas alterações dado a características particulares, por um lado, o maior desenvolvimento industrial faz com que as taxas de informalidade, sejam menores, se comparada à média nacional, porém, apresentou-se crescente no período, saltando de 38,6\% em 1992 para 44,4\% em 1999. Por outro lado, as taxas de desemprego apresentaram médias superiores e crescimento percentual maior às médias nacionais, passando de 8,8\% em 1992 para 12,9\% em 2009.

$\mathrm{Na}$ década seguinte - apesar da continuidade da aplicação das políticas neoliberais o crescimento do Produto Interno Bruto a partir de 2003 estimulado, sobretudo, pela dinamização do setor de serviços, fez o desemprego e a informalidade apresentarem uma trajetória decrescente no Brasil e no Estado de São Paulo. De acordo com Pochmann (2013) na primeira década do século XXI somente o setor terciário tem registrado aumento na sua posição relativa em relação ao PIB, gerando 2,3 vezes mais empregos do que o setor secundário.

Os dados do IBGE explicitam estatisticamente a redução do desemprego e da informalidade.

Tabela 2 - Evolução da taxa de desemprego e informalidade entre 2001 e 2009 no Brasil e no Estado de São Paulo (\%)

\begin{tabular}{ccccc}
\hline Período & $\begin{array}{c}\text { Taxa de } \\
\text { Desemprego } \\
(\boldsymbol{\%})\end{array}$ & $\begin{array}{c}\text { Taxa de } \\
\text { Desemprego } \\
\text { Brasil }\end{array}$ & $\begin{array}{c}\text { Taxa de } \\
\text { Informalidade Paulo } \\
(\boldsymbol{\%}) \text { Brasil }\end{array}$ & $\begin{array}{c}\text { Taxa de } \\
\text { Informalidade } \\
(\boldsymbol{\%}) \text { em SP }\end{array}$ \\
\hline 2001 & 10,0 & 11,5 & 55,1 & 43,4 \\
2002 & 9,9 & 11,8 & 55,3 & 44,2 \\
2003 & 10,5 & 12,6 & 54,3 & 43,4 \\
2004 & 9,7 & 11,5 & 53,8 & 42,6 \\
2005 & 10,2 & 11,8 & 53,1 & 42,5 \\
2006 & 9,2 & 10,2 & 52,1 & 41,1 \\
2007 & 8,9 & 9,5 & 50,8 & 39,4 \\
2008 & 7,8 & 8,2 & 49,2 & 37,9 \\
2009 & 9,1 & 9,8 & 48,7 & 37,1 \\
\end{tabular}

Fonte: IBGE/ IPEAdata. Org. Victor Hugo Junqueira 
A queda nas taxas de desemprego e de informalidade evidenciada pelos dados oficiais foi acompanhada pela contratação de um grande número de trabalhadores em serviços com baixa remuneração, com contratos precários e que impactaram em uma alta rotatividade da força de trabalho (ALVES, 2012).

Para exemplificar esta realidade selecionamos os dados de geração de empregos formais no país, disponibilizados pelo Cadastro Geral de Empregos (Caged) do Ministério do Trabalho e Emprego, para o período de 2007 a $2010^{5}$.

Tabela 3 - Distribuição da geração de empregos segundo salário mensal 2007, 2008 e 2010 - Brasil em (\%)

\begin{tabular}{|c|c|c|c|}
\hline \multirow[t]{2}{*}{ Faixa de salários } & \multicolumn{3}{|c|}{ Participação no Saldo Total } \\
\hline & 2007 & 2008 & 2010 \\
\hline Até 0,5 & 1,5 & 1,8 & 1,9 \\
\hline De 0,51 a 1,0 & 30,5 & 35,5 & 32,2 \\
\hline De 1,01 a 1,5 & 63,0 & 71,6 & 66,0 \\
\hline De 1,51 a 2,0 & 17,7 & 12,0 & 14,1 \\
\hline De 2,01 a 3,0 & $-2,4$ & $-8,2$ & -6.0 \\
\hline De 3,01 a 4,0 & $-2,9$ & $-5,0$ & -3.5 \\
\hline De 4,01 a 5,0 & $-2,9$ & $-2,8$ & $-1,8$ \\
\hline De 5,01 a 7,0 & $-2,3$ & $-3,3$ & $-1,8$ \\
\hline De 7,01 a 10,0 & $-1,0$ & $-0,8$ & $-0,6$ \\
\hline De 10,1 a 15,0 & $-0,9$ & $-0,9$ & $-0,6$ \\
\hline De 15,01 a 20,0 & $-0,3$ & $-0,4$ & $-0,2$ \\
\hline Mais de 20 & $-0,7$ & $-0,8$ & $-0,4$ \\
\hline Ignorado & 0,8 & 1,2 & 0,7 \\
\hline Total & 100,0 & 100,0 & 100,0 \\
\hline $\begin{array}{l}\text { Total (em } \mathrm{n}^{\circ} \\
\text { absoluto) }\end{array}$ & 1.617 .392 & 1.452 .204 & 2.136 .947 \\
\hline
\end{tabular}

Fonte: Caged (MTE)/ Dieese. Org. Victor Hugo Junqueira

Os resultados da tabela mostram que no período considerado mais de $90 \%$ das vagas de empregos formais gerados no país se concentraram na faixa entre de 0,5 a 1,5 salários mínimos, enquanto nas faixas salariais superiores a dois salários mínimos, os saldos foram negativos. Em suma, a geração de empregos no Brasil representa a inserção de parcelas da população em serviços precários e mal remunerados.

Os dados sobre a geração de empregos no Estado de São Paulo indicam a mesma tendência, alta rotatividade na geração de empregos, com baixa remuneração. A tabela a seguir (tabela 4) exibe o saldo dos 20 postos de trabalho que mais geraram empregos formais entre 2007 e 2010 no Estado de São Paulo, conforme dados do MTE/Caged. 
Tabela 4 - 20 postos de trabalho que mais geraram empregos formais entre 2007 e 2010 no Estado de São Paulo.

\begin{tabular}{|c|c|c|c|c|}
\hline Empregos & $\begin{array}{l}\text { Salário Médio de } \\
\text { Admissão. }\end{array}$ & Admissão & Desligamento & Saldo \\
\hline Alimentador de Linha de Produção & 565,66 & 762.165 & 591.216 & 170.949 \\
\hline Auxiliar de Escritório, em Geral & 584,68 & 990.209 & 845.940 & 144.269 \\
\hline Servente de Obras & 580,33 & 780.857 & 653.478 & 127.379 \\
\hline Vendedor de Comercio Varejista & 548,07 & 1.256 .564 & 1.149 .617 & 106.947 \\
\hline $\begin{array}{lll}\text { Faxineiro }^{6} & \text { (Desativado em } \\
01 / 2009)^{2} & \end{array}$ & 276,76 & 429.851 & 358.345 & 71.506 \\
\hline Assistente Administrativo & 898,54 & 490.341 & 419.589 & 70.752 \\
\hline Embalador, a Mão & 447,41 & 248.185 & 189.720 & 58.465 \\
\hline Faxineiro (Desativado em 2010) & 552,63 & 370.511 & 317.119 & 53.392 \\
\hline $\begin{array}{l}\text { Operador de Telemarketing Ativo } \\
\text { e Receptivo }\end{array}$ & 406,85 & 405.310 & 357.761 & 47.549 \\
\hline Ajudante de Motorista & 530,55 & 214.988 & 170.819 & 44.169 \\
\hline Recepcionista, em Geral & 553,32 & 276.531 & 233.033 & 43.498 \\
\hline Vigilante & 672,67 & 214.658 & 174.032 & 40.626 \\
\hline Atendente de Lanchonete & 431,8 & 347.214 & 308.447 & 38.767 \\
\hline $\begin{array}{l}\text { Operador de } \\
\text { Receptivo }\end{array}$ Telemarketing & 481,29 & 229.034 & 192.157 & 36.877 \\
\hline Operador de Caixa & 546,13 & 340.500 & 305.755 & 34.745 \\
\hline Repositor de Mercadorias & 506,68 & 266.278 & 233.910 & 32.368 \\
\hline $\begin{array}{l}\text { Motorista de Caminhão (Rotas } \\
\text { Regionais e Internacionais) }\end{array}$ & 748,25 & 407.951 & 381.189 & 26.762 \\
\hline Porteiro de Edifícios & 495,36 & 299.271 & 272.860 & 26.411 \\
\hline Cozinheiro Geral & 501,85 & 305.640 & 280.067 & 25.573 \\
\hline Almoxarife & 642,56 & 197.983 & 175.857 & 22.126 \\
\hline
\end{tabular}

Fonte: MTE/Caged.

Os postos de trabalho que apresentaram maiores saldos no estado de São Paulo no período são caracterizados pela exigência de baixa qualificação, concentrando-se na faixa salarial de até um salário mínimo e com alta rotatividade, dado o número elevado de admissões e desligamentos.

Contudo, apesar de estarmos considerando dados oficiais, Alves (2012, p.7) desvela que:

a precariedade do emprego no Brasil na década de 2000 tende a ser ocultada, por um lado, pelo alto índice de rotatividade da força de trabalho tendo em vista a demissão imotivada, e, por outro lado, pela invisibilidade socioestatística de amplo espectro da precariedade contratual do mundo do trabalho, que ocorre por meio das relações de emprego disfarçadas (contratação como pessoa jurídica - $\mathrm{PJ}$, cooperativas de contratação de trabalho, trabalho/estágio, "autônomos", trabalho em domicílio e teletrabalho, etc.).

Assim, a precariedade se manifesta tanto nas relações formais de emprego, vislumbradas nas análises estatísticas oficiais, quanto nas novas formas de precariedade 
contratual - conveniente ao modelo de acumulação flexível - ou por serem invisíveis às regras trabalhistas ou por transformar o trabalhador em empresa.

Outra observação importante, para caracterizarmos o mercado de trabalho brasileiro é o grau de instrução das pessoas que estão sendo admitidas em empregos formais. A tabela 5, organizada a partir de dados do MTE/Caged apresenta participação na geração de empregos por grau de escolaridade no Brasil entre 2007 e $2010^{7}$.

Tabela 5 - Distribuição da geração de empregos segundo grau de escolaridade 2007, 2008 e 2010- Brasil em (\%)

\begin{tabular}{|c|c|c|c|}
\hline \multirow[t]{2}{*}{ Grau de Instrução } & \multicolumn{3}{|c|}{ Participação no Saldo Total } \\
\hline & 2007 & 2008 & 2010 \\
\hline Analfabeto & 0,1 & 0,1 & 0,0 \\
\hline $\begin{array}{l}\text { Até o } 5^{\circ} \text { ano Incompleto do Ensino } \\
\text { Fundamental }\end{array}$ & $-0,4$ & $-0,9$ & 2,2 \\
\hline $\begin{array}{l}5^{\circ} \text { ano Completo do Ensino } \\
\text { Fundamental }\end{array}$ & $-1,0$ & $-2,3$ & $-1,5$ \\
\hline $\begin{array}{l}\text { Do } 6^{\circ} \text { ao } 9^{\circ} \text { ano Incompleto do } \\
\text { Ensino Fundamental }\end{array}$ & 4,3 & 2,4 & 2,4 \\
\hline Ensino Fundamental Completo & 8,7 & 6,1 & 7,2 \\
\hline Ensino Médio Incompleto & 10,1 & 9,0 & 9,9 \\
\hline Ensino Médio Completo & 64,0 & 67,4 & 65,5 \\
\hline Educação Superior Incompleta & 5,5 & 6,9 & 4,7 \\
\hline Educação Superior Completa & 8,7 & 11,5 & 9,6 \\
\hline Ignorado & 0,0 & 0,0 & 0,0 \\
\hline Total & 100,0 & 100,0 & 100,0 \\
\hline Total (em no absoluto) & 1.617 .392 & 1.452 .204 & 2.136 .947 \\
\hline
\end{tabular}

Fonte: MTE/Caged. Dieese. Org. Victor Hugo Junqueira

Os dados do MTE/Caged indicam que a geração de empregos no país se concentra entre pessoas com ensino médio completo e vai reduzindo para os graus de menor escolaridade. Entre 2007 e 2010 mais de 60\% da mão-de-obra contratada tinha o ensino médio completo. Estes dados, apenas comprovam a tendência a ampliação da escolaridade média dos trabalhadores nas últimas décadas, com a redução dos índices de analfabetismo, universalização do ensino fundamental e progressiva ampliação da oferta do ensino médio pelo Estado.

Nesse sentido, partindo da afirmação inicial da centralidade no trabalho e da educação determinada pelo modo de produção, quais os nexos e significados da educação escolar com as relações de trabalho no atual estágio de desenvolvimento capitalista? Qual a função da escolarização básica, em particular do Ensino Médio, no contexto de complexificação e fragmentação do mundo do trabalho?

Sem a pretensão de responder a estes questionamentos, para os quais são necessários um conjunto de pesquisas e investigações em diferentes campos disciplinares, nos limitamos a esboçar algumas considerações sobre o discurso que vincula o Ensino Médio com o mundo do trabalho na Proposta Curricular do Estado de São Paulo a luz do comportamento da evolução da geração de emprego e renda no país e em específico no Estado de São Paulo, sob o modo de produção flexível. 


\section{A articulação do Ensino Médio com o mundo do trabalho: análise do Currículo da rede estadual de São Paulo.}

No ano de 2007, primeiro ano do governo José Serra ${ }^{8}$ do Partido da Social Democracia Brasileira - PSDB - partido que governa o Estado desde 1995 -, a Secretaria do Estado da Educação do Estado de São Paulo (SEE/SP) comandada por Maria Helena Guimarães de Castro, propôs um conjunto de 10 metas $^{9}$ a serem atingidas até o final de 2010 objetivando a "melhoraria efetiva do aprendizado em nossas escolas" conforme declarou a própria secretária em artigo publicado na Folha de São Paulo em 20 de agosto de 2007.

As metas que incidiam diretamente sobre o Ensino Médio eram: 3 - redução de $50 \%$ das taxas de reprovação; 5 - aumento de 10\% nos índices de desempenho nas avaliações nacionais e estaduais; e 6 - atendimento de $100 \%$ da demanda de jovens e adultos de Ensino Médio com oferta diversificada de currículo profissionalizante.

Para cumprir cada uma das metas o governo propôs também 10 ações ${ }^{10}$ que orientariam as políticas educacionais, entre elas a diversificação curricular do Ensino Médio, organizadas em três grandes eixos:

1 - a partir de uma base comum de conteúdos e competências, o estudante poderá optar por habilitações técnicas profissionalizantes;

2 - Oferta, a partir de 2008, da modalidade "técnico em administração" em 20\% dos cursos noturnos de Ensino Médio, em parceria com o Centro Paula Souza;

3 - Parcerias com o setor privado para certificações parciais em computação e língua estrangeira.

Para garantir a base comum de conteúdos e competências (eixo 1) a Secretaria do Estado de Educação implantou em 2008 uma nova Proposta Curricular, transformada em Currículo no ano seguinte, representando uma estratégia importante para a viabilização das políticas neoliberais no interior da escola, alicerçadas nos discursos e conceitos da pedagogia do aprender a aprender. (DUARTE, 2001)

O Currículo do Estado de São Paulo propõe uma educação à altura dos desafios contemporâneos em uma sociedade caracterizada pelo uso intensivo do conhecimento, que têm gerado uma nova exclusão - tão indesejável quanto a exclusão aos bens materiais "ligado ao uso das tecnologias que mediam o acesso de comunicação que hoje medeiam o acesso ao conhecimento ou aos bens culturais" (SÃO PAULO, 2010, p.8).

A escola pública ao receber cada vez mais as camadas pobres da sociedade brasileira, deve contribuir para a "real oportunidade de inserção produtiva e solidária no mundo" por meio da universalização da relevância da aprendizagem, na medida em que "apenas uma educação de qualidade para todos pode evitar que essas diferenças (culturais, sociais e econômicas) se constituam em mais um fator de exclusão" (SÃO PAULO, 2010, p.9).

O Currículo do Estado de São Paulo ainda sustenta que:

A autonomia para gerenciar a própria aprendizagem (aprender a aprender) e para a transposição dessa aprendizagem em intervenções solidárias (aprender a fazer e a conviver) deve ser a base da educação das crianças, dos jovens e dos adultos, que têm em suas mãos a continuidade

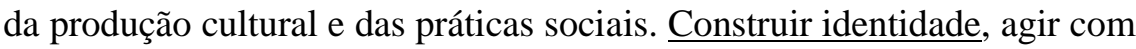


autonomia e em relação com o outro, bem como incorporar a diversidade, são as bases para a construção de valores de pertencimento e de responsabilidade, essenciais para a inserção cidadã nas dimensões sociais e produtivas. (SÃO PAULO, 2010, p.10 destaque nosso).

Desta forma, o Currículo paulista alinhado aos princípios das pedagogias do aprender a aprender difundidas ao mundo após a Conferência Mundial Educação para Todos realizada em 1990 em Jomtien - Tailândia (DELORS, 1998) desloca a liberdade de ensino para o direito de aprender e define como eixos centrais: currículo como espaço de cultura; as competências como eixo de aprendizagem; a prioridade da competência de leitura e de escrita; a articulação das competências para aprender e a contextualização no mundo do trabalho. (SÃO PAULO, 2010)

A articulação com o mundo do trabalho coloca-se como uma das prioridades para o Ensino Médio, justificando a consonância com as formulações da Lei de Diretrizes e Bases da Educação (Lei no 9.394/96) e as Diretrizes Curriculares Nacionais para o Ensino Médio (DCNEM).

Esta articulação assume dois sentidos complementares, "como valor, imprime importância ao trabalho e cultiva o respeito que lhe é devido na sociedade, e como tema, que perpassa os conteúdos curriculares, atribuindo sentido aos conhecimentos específicos das disciplinas" (SÃO PAULO, 2010, p.23)

Assim, o Currículo procura romper com a dicotomia que separa a formação profissional da formação geral, pois

À medida que a tecnologia vai substituindo os trabalhadores por autômatos na linha de montagem e nas tarefas de rotina, as competências para trabalhar em ilhas de produção, associar concepção e execução, resolver problemas e tomar decisões tornam-se mais importantes do que conhecimentos e habilidades voltados para postos específicos de trabalho. (SÃO PAULO, 2010, p. 23)

O Currículo oficial Paulista transparece estar em sintonia com o mercado de trabalho cada vez mais exigente de conhecimento e de pessoas com habilidades e competências cognitivas e comportamentais necessárias a flexibilidade e adaptabilidade da sociedade do conhecimento. Ocorre que este não é o mundo real.

Sob a promessa de inserção cidadã nas dimensões sociais e produtivas do capitalismo, o Estado serve aos preceitos neoliberais da construção de uma ideologia da "sociedade do conhecimento" que mascara os reais processos de reprodução de um capitalismo cada vez mais excludente (DUARTE, 2001).

Como observamos a dinâmica do mundo do trabalho no Brasil e no Estado de São Paulo, para a grande parcela da população pobre que está na escola pública as perspectivas do ingresso no mercado de trabalho, se apresentam nas formas de trabalhos precários, mal remunerados e exigentes de pouca qualificação técnica, ainda que exigentes de maior escolaridade, na medida em que as contratações na primeira década do século XXI tem se concentrado entre os que possuem ensino médio.

A ampliação da oferta e do número de matrículas no Ensino Médio na rede Estadual de Ensino que em 2012 representou 80,9\% das matrículas do Estado ${ }^{11}$, a despeito de todo o discurso da melhoria da qualidade e da articulação com o trabalho, não tem significado um aprendizado efetivo, uma vez que é da própria lógica do capitalismo contemporâneo, a exploração de uma grande massa de mão-de-obra adestrada, mas pouco qualificada. 
Nesse sentido, a observação de Braverman (1987, p. 372) continua atual:

As escolas como babás de crianças e jovens, são indispensáveis para o funcionamento da família, da estabilidade da comunidade e ordem social em geral (embora elas preencham mal essas funções). Numa palavra, já não há mais lugar para o jovem na sociedade a não ser na escola. Servindo para preencher um vácuo, as próprias escolas tornaram-se um vácuo, cada vez mais vazio de conteúdos e reduzidas a pouco mais que suas próprias formas (BRAVERMAN, 1987, p. 372) .

O Ensino Médio no Estado de São Paulo etapa de formação geral e com o discurso que o atrela ao mundo do trabalho, está muito longe de fornecer até mesmo os conhecimentos mais primários exigidos neste nível de ensino, as próprias avaliações externas do governo tem comprovado isto. O resultado do Sistema de Avaliação de Rendimento Escolar do Estado de São Paulo - SARESP (tabelas 6 e 7) mostram como a maioria dos estudantes paulistas apresentam conhecimentos básicos e abaixo do básico em Língua Portuguesa e Matemática.

Tabela 6 - Distribuição Percentual dos alunos nos níveis de proficiência da Rede Estadual de Ensino de São Paulo em Língua Portuguesa - SARESP 2008, 2009, 2010 e 2011.

\begin{tabular}{lcccc}
\hline Nível de Proficiência & $\mathbf{2 0 0 8}$ & $\mathbf{2 0 0 9}$ & $\mathbf{2 0 1 0}$ & $\mathbf{2 0 1 1}$ \\
\hline Abaixo do Básico & 32,9 & 29,5 & 37,9 & 37,5 \\
Básico & 37,7 & 40,6 & 38,3 & 38,4 \\
Adequado & 28,6 & 29,2 & 23,3 & 23,4 \\
Avançado & 0,9 & 0,7 & 0,6 & 0,7 \\
\hline
\end{tabular}

Fonte: Secretaria do Estado da Educação- SP. Org. Victor Hugo Junqueira

Tabela 7 - Distribuição Percentual dos alunos nos níveis de proficiência da Rede Estadual de Ensino de São Paulo em Matemática-SARESP 2008, 2009, 2010 e 2011.

\begin{tabular}{lcccc}
\hline Nível de Proficiência & $\mathbf{2 0 0 8}$ & $\mathbf{2 0 0 9}$ & $\mathbf{2 0 1 0}$ & $\mathbf{2 0 1 1}$ \\
\hline Abaixo do Básico & 54,3 & 58,3 & 57,7 & 58,4 \\
Básico & 40,5 & 36,8 & 38,4 & 37,1 \\
Adequado & 4,8 & 4,4 & 3,6 & 4,2 \\
Avançado & 0,4 & 0,5 & 0,3 & 0,3 \\
\hline
\end{tabular}

Fonte: Secretaria do Estado da Educação- SP. Org. Victor Hugo Junqueira

Isto posto, para a grande massa de trabalhadores e filhos de trabalhadores que estão na escola pública, o conhecimento continua prescrito em doses prudentemente homeopáticas conforme já sugeria Adam Smith, contudo, alimentando a ilusão de uma sociedade do conhecimento (DUARTE, 2001) que abre oportunidades a todos a um 
pseudo-mundo de trabalhos qualificados, exigente de competências e habilidades cognitivas para resolver situações complexas, além de "culpabilizar" os indivíduos pelo fracasso na inserção profissional (ALVES, 2007).

Para Kuenzer (2007) o que caracteriza o discurso da educação no regime de acumulação flexível é a negação da dualidade estrutural do capitalismo, que se fundamenta na

[...] exclusão includente na ponta do mercado, que exclui para incluir em trabalhos precarizados ao longo das cadeias produtivas, dialeticamente complementada pela inclusão excludente na ponta da escola, que, ao incluir em propostas desiguais e diferenciadas, contribui para a produção e para a justificação da exclusão (KUENZER, 2007, p.1165).

Para o projeto neoliberal e de acumulação flexível do capitalismo, a educação para a massa de trabalhadores deve continuar a cumprir o papel da manipulação ideológica a serviço do capital, seja para o disciplinamento na produção ou no consumo ou naturalização das desigualdades criadas pelo capitalismo, que segundo o Currículo paulista é derivado da "remuneração injusta do trabalho" (SÃO PAULO, 2010, p.22) Além disso, é cada vez mais evidente que o Ensino Médio cumpre a função de ser critério de seleção e um meio do Estado controlar o tempo de inserção de jovens no mercado de trabalho marcado pelo desemprego estrutural.

O ensino médio vinculado ao trabalho seja no Currículo oficial, ou como sugerido nas propostas de Ensino Integral do Estado de São Paulo ${ }^{12}$ e no Projeto Vence ${ }^{13}$ combina de um lado o aumento da permanência dos jovens na escola, e por outro, a privatização do ensino público.

Por outro lado, não temos dúvidas, que a dinâmica da acumulação flexível, exige, também trabalhadores com conhecimentos necessários a operação e reprodução técnica, automativa, administrativa, informacional, entre outras; em resumo, trabalhadores "qualificados tecnicamente" e adestrados para servir a determinados processos de valorização do capital seja nas operações industriais, como no setor de serviços.

De acordo com pesquisa da Confederação Nacional das Indústrias (CNI) realizada em 2011, 59\% das empresas industriais pesquisadas enfrentavam dificuldades com a falta de trabalhador qualificado e o principal argumento das indústrias para esta situação está na baixa qualidade da educação básica. Estaríamos, então diante da necessidade do capital estimular a educação básica de qualidade para a classe trabalhadora?

Obviamente, a resposta é negativa. A própria pesquisa da CNI revela que a principal estratégia das indústrias tem sido a capacitação na própria empresa (78\%). Além disso, sugerimos, que no Estado de São Paulo a saída encontrada tem sido a oferta de cursos técnicos descentralizados e servindo aos interesses do capital de acordo com as necessidades locais.

Certamente, este aspecto precisa ser investigado, mas a expansão das Escolas Técnicas e Faculdades de Tecnologias no Estado de São Paulo apontam nesta direção. Em 2007, Governo Serra, lançou um massivo projeto de expansão da rede de Escolas Técnicas Estaduais (Etecs) e Faculdades de Tecnologia (Fatecs) no Estado de São Paulo.

No lançamento do programa a Secretaria do Desenvolvimento, Ciência e Tecnologia a quem é vinculada a rede técnica declarou em seu site oficial ${ }^{14}$ que a iniciativa de construção das escolas técnicas pode partir do Estado, dos municípios ou das empresas privadas, diante disso, "são identificados os dados demográficos e econômicos da região e estabelecido um trabalho conjunto com a prefeitura e o setor produtivo local para a definição dos cursos a serem ministrados'. 
Após o programa de expansão das 26 Faculdades de Tecnologia existentes em 2006 saltaram para 51 atendendo cerca de 50 mil alunos em 60 cursos de graduação tecnológica em 2013. Já as Escolas Técnicas Estaduais criaram a partir de 2006 mais de 100 mil vagas, atendendo em 2013, 216 mil estudantes nos Ensinos Técnico e Médio, nos mais de 100 cursos técnicos para os setores industrial, agropecuário e de serviços em 155 municípios do estado.

Ainda que sem um exame mais pormenorizado, o programa de expansão da rede técnica de "qualificação" para o trabalho indica o papel do Estado em atender a necessidades pontuais e geograficamente localizado do capital, na direção de suprimir as defasagens do ensino médio e conformar e treinar a classe trabalhadora ao processo incessante de reprodução do capital.

\section{Considerações Finais}

A reestruturação toyotista do capital impôs a complexificação, fragmentação e flexibilização das relações de trabalho, capturando de um lado a subjetividade dos trabalhadores, na sua capacidade imanente de criação e colocando-a a serviço da valorização do capital e por outro, ampliou a grande massa de trabalhadores que negada em sua capacidade criadora, continua a desempenhar funções simples, igualmente necessárias a valorização do capital.

O que há em comum entre estas duas funções é a libertação do trabalhador dos meios de produção e o seu cativeiro no trabalho, pois só o trabalho, como essência humana, e pelo trabalho pode-se produzir a existência. Uma vez negado e alienado dos meios de produção no capitalismo, só pode produzir sua existência transformando-se mercadoria a serviço da valorização do capital daqueles que possuem os meios de produção, seja em funções manualmente e tecnicamente simples ou em funções intelectualmente complexas.

Com efeito, a reestruturação produtiva do capital, estágio mais avançado de desenvolvimento do capital, não pode negar o que está na sua essência: a exploração do trabalhador para sua reprodução incessante. Ao contrário, ao comprimir o espaço-tempo da produção de mercadorias (HARVEY, 1992), intensifica a exploração dos trabalhadores em suas diferentes formas (qualificados ou não qualificados, formais ou informais), ao mesmo tempo, que dado ao seu desenvolvimento técnico-científico amplia a massa de trabalhadores desempregados.

Esta leitura do real, não permite outra afirmação senão a centralidade no trabalho como dimensão ontológica do ser humano e como categoria analítica da realidade. Nesta perspectiva, a educação escolar como uma das instituições sociais colocadas a serviço do capital está pari passu com o desenvolvimento do modo de produção e das relações de trabalho que lhe são inerentes.

No atual estágio de desenvolvimento capitalista e as implicações do movimento desigual e combinado do capitalismo brasileiro, a educação escolar básica, continua a manifestar a sua dualidade estrutural (KUENZER, 2007), entretanto, sob um viés de inclusão e democratização do acesso ao conhecimento.

No estado do São Paulo, o Currículo e as políticas estaduais paulistas desenvolvidas sob comando dos governos neoliberais, ao definir a vinculação do contexto do trabalho como prioridade para o Ensino Médio, objetiva legitimar os processos excludentes e precarizados do mundo do trabalho na acumulação flexível, sob a ilusão de uma sociedade do conhecimento, exigente de competências e habilidade comportamentais e cognitivas complexas. Concomitantemente, ao pretender universalizar o ensino médio e 
ampliar o tempo de permanência na escola estabelece um controle sob a ordem social e a pressão exercida por aqueles que almejam entrar no mundo do trabalho sem capacidade de absorver a todos.

Entretanto, como já afirmamos o capital não é um bloco monolítico que arrasta a tudo e todos permanentemente, mas que se move com fissuras, obstáculos e contradições. A alienação do trabalho por mais perversa que se apresente sob o capitalismo, não suprime a dimensão ontológica e criativa do trabalho e a sua possibilidade histórica de transformação das condições sociais.

Na mesma direção, como afirma Mészáros (2005) a educação, ao mesmo tempo em que constitui-se num dos instrumentos fundamentais da produção das condições objetivas de manutenção da ordem social do capital, fazendo com que os indivíduos "internalizem" os valores e a moral do capitalismo, legitimando-o, é também necessária para pensar em uma estratégia de transformação social que esteja para além do capital.

O vir-a-ser como um campo aberto de possibilidades, não pode negar a priori a alternativa de uma sociedade que esteja para além do capital, para tanto, é preciso explorar as fissuras e contradições do capital, inclusive, no campo educacional fazendo a disputa política em defesa de uma pedagogia que projete uma sociedade para além do capital.

\section{Referências}

ALVES, G. Dimensões da reestruturação produtiva. Ensaios de Sociologia do trabalho. Londrina: Praxis; Bauru: Canal 6, 2007.

Trabalho e nova precariedade salarial no Brasil. Morfologia Social do Trabalho na década de 2000. Oficina do Centro de Estudos Sociais, Faculdade de Economia, Universidade de Coimbra. 2012. Disponível em: < http://www.ces.uc.pt/publicacoes/oficina/index.php?id=6024> Acesso em: 10 de abril de 2013.

ANTUNES, R. A desertificação neoliberal: (Collor, FHC, Lula). Campinas: Autores Associados, 2004.

ANTUNES, R. Adeus ao trabalho? Ensaios sobre as metamorfoses e a centralidade do mundo do trabalho. Campinas: Editora Cortez, 2011.

ANTUNES, R.; ALVES, G. As mutações do trabalho na era da mundialização do capital. Educ. Soc., Campinas, vol. 25, n. 87, p. 335-351, maio/ago. 2004. Disponível em <http://www.cedes.unicamp.br> Acesso em: 10 de maio de 2013.

BRAVERMAN, H. Trabalho e capital monopolista. A degradação do trabalho no século XX. Rio de Janeiro: LTC editora, 1987.

CONFEDERAÇÃO NACIONAL DA INDÚSTRIA (CNI). Falta de trabalhador qualificado na indústria. Sondagem especial, Rio de Janeiro, ano 9, n. 2, abril de 2011. Disponível em: <www.cni.org.br> Acesso em 02 de junho de 2013.

DELORS, J., (org.) (1998). Educação: um tesouro a descobrir. São Paulo: Cortez, Brasília, DF: MEC: UNESCO

DUARTE, N. As pedagogias do aprender a aprender e algumas ilusões da assim chamada sociedade. Revista Brasileira de Educação, Rio de Janeiro, n.18 p. 35-40, set/out/nov/dez 2001. 
ENGELS, F. Sobre o papel do trabalho na transformação do Macaco em Homem. In: ANTUNES, R (org.). A dialética do trabalho. Escritos de Marx e Engels.São Paulo: Expressão Popular, 2004.

A origem da família, da propriedade privada e do Estado. Rio de Janeiro: Civilização Brasileira, 1984.

HARVEY, D. A condição pós-moderna: Uma pesquisa sobre a origem da mudança cultural. São Paulo: Edições Loyola, 1992.

A produção capitalista do espaço. São Paulo: Annablume. 2005.

KUENZER, A. Z. Da dualidade assumida à dualidade negada: o discurso da flexibilização justifica a inclusão excludente. Educ. Soc., Campinas, vol. 28, n. 100 - Especial, p. 11531178, out. 2007. Disponível em <http://www.cedes.unicamp.br> Acesso em 14 de maio de 2013

LOMBARDI, J.C. Reflexões sobre educação e ensino na obra de Marx e Engels. 2010. 377 f. Tese (Livre Docência) - Faculdade de Educação, Universidade Estadual de Campinas, Campinas.

MARX, K. Manuscritos econômico-filosóficos. Lisboa: Edições 70, 1989.

MARX, K. O capital. Crítica da economia política. Os Economistas. Volume 1, livro 1. O processo de produção do capital. São Paulo: Nova Cultural. 1996.

MARX, K. \& ENGELS, F. Ideologia Alemã. Crítica a novíssima filosofia alemã em seus representantes Feurbach, B. Bauer e Stirner, e do Socialismo alemão em seus diferentes profetas. Rio de Janeiro: Civilização Brasileira. (1845-1846). 2007.

MÉSZÁROS, I. Educação para além do capital. São Paulo: Boitempo, 2005.

POCHMANN, M. O trabalho sob fogo cruzado: exclusão, desemprego e precarização no final do século. São Paulo: Contexto. 1999.

Políticas públicas e situação social na primeira década do século XXI . In: SADER, E. (org.). 10 anos de governos pós-neoliberais no Brasil: Lula e Dilma. São Paulo, SP: Boitempo; Rio de Janeiro: FLACSO Brasil 2013.

PONCE, A. Educação e luta de classes. São Paulo: Cortez, 2005.

RUSSO, M.; CARVALHO, C. A política educacional do governo Serra. 2009. Disponível em: www.simposioestadopoliticas.ufu.br/imagens/anais/pdf/C38.pdf. Acesso em: 22 mai. 2013.

SANTOS, M. Por uma outra globalização: do pensamento único à consciência universal. São Paulo: Record, 2008.

SÃO PAUlO (Estado). Secretaria do Estado da Educação. Currículo do Estado de São Paulo: Ciências Humanas e suas tecnologias. São Paulo: SEE, 2010. 152 p.

SAVIANI, D. Trabalho e Educação: Fundamentos Ontológicos e Históricos. Revista Brasileira de Educação, São Paulo, ano/vol. 12, numero 034, p. 152-165, jan-abr. 2007.

SANFELICE, J. L. A política educacional do Estado de São Paulo: apontamentos. Nuances: estudos sobre Educação, Presidente Prudente, v. 17, n. 18, p. 146-159, jan./dez. 2010. 


\section{Notas:}

${ }^{1}$ Mestrando no Programa de Pós-Graduação em Educação da Universidade Federal de São Carlos (UFSCar);
Professor de Geografia na Educação Básica nos níveis Fundamental e Médio e na Educação Superior na
modalidade a distância do Centro Universitário Claretiano de Batatais-SP. É membro Grupo de Estudos e Pesquisas em Educação do Campo - GEPEC/UFSCar.

${ }^{2}$ Professora Adjunta no Departamento de Educação da Universidade Federal de São Carlos DED/UFSCar; Professora do Programa de Pós-Graduação em Educação/UFSCar; Membro do Grupo de Pesquisa em Educação do Campo - GEPEC/UFSCar.

${ }^{3}$ O IBGE utiliza três definições para taxa de informalidade, consideramos a definição I que corresponde ao resultado da seguinte divisão: (empregados sem carteira + trabalhadores por conta própria)/ (trabalhadores protegidos + empregados sem carteira + trabalhadores por conta própria).

${ }^{4}$ Não houve pesquisa em 1994.

${ }^{5}$ Os dados de 2010, organizados pelo Dieese, sintetizam o resultado dos anos de 2009 e 2010.

${ }^{6}$ Mudança no Código do emprego no CAGED.

${ }^{7}$ Os dados de 2010, organizados pelo Dieese, sintetizam o resultado dos anos de 2009 e 2010.

${ }^{8}$ Conforme os estudos de Russo e Carvalho (2009) e Sanfelice (2010) mostraram, a política educacional do governo Serra (2007-2010) iniciada por Maria Helena Guimarães de Castro e continuada a partir de 2009 por Paulo Renato Souza (ex-ministro da Educação do governo FHC) buscaram transpor para a educação pública os preceitos empresariais de melhor gestão, eficiência e quantificação e bonificação por resultados, ampliação da competitividade entre professores e privatização da escola transformando a escola pública paulista em um laboratório privilegiado das políticas neoliberais de mercantilização da educação.

9 As 10 metas estão disponíveis em:<http://www.saopaulo.sp.gov.br/spnoticias/lenoticia.php?id=87027> Acesso em: 15 de junho de 2013.

10 As 10 ações estão disponíveis em 〈http://www.saopaulo.sp.gov.br/acoes/educacao/metas/acoes.htm〉 Acesso em: 15 de junho de 2013.

${ }^{11}$ SÃO PAULO. Secretaria do Estado da Educação. Série Histórica Matrícula da Educação Básica Estado de São Paulo. Tabelas 1985, 1990, 1995, $2012 . \quad$ Disponível em: < http://www.educacao.sp.gov.br/docs/SH_Total_do_Estado_2012_TABELAS\%20e\%20GR\%C3\%81FICOS \%20EM\%20PDF.pdf> Acesso em 10 de junho de 2013.

12 Programa instituído pela Secretaria da Educação em 2012 com objetivo de ampliar o tempo de permanência do jovem na escola. As diretrizes do programa estão disponíveis em: < http://www.educacao.sp.gov.br/a2sitebox/arquivos/documentos/342.pdf $>$. Acesso em 12 de junho de 2013.

13 Programa da Secretaria da Educação do Estado de São Paulo, que procura articular o ensino médio ao ensino técnico. Por este programa $\mathrm{p}$ governo do Estado realiza convênio com instituições públicas ou privadas para oferecer cursos técnicos aos alunos da rede estadual em duas modalidades: a integrada e a concomitante. A primeira é destinada a alunos do $1^{\circ}$ ano na qual ele cursa o Ensino Médio e o Técnico em um só período nos Centros Paula Souza ou nos Institutos Federais de Educação; já a segunda modalidade é destinada a alunos do $2^{\circ}$ e $3^{\circ}$ anos e da Educação de Jovens e Adultos, nela o aluno frequenta o Ensino Médio na rede estadual em um período e faz o curso técnico em uma instituição credenciada em outro. Disponível em: <http://www.vence.sp.gov.br/remt/av/Padrao/aplicacao-site/> Acesso em: 10 de junho de 2013.

14 Informação disponível em: <http://www.desenvolvimento.sp.gov.br/noticias/?ID=808> acesso em 10 de junho de 2013.

Recebido: $\quad$ agosto/13 $\quad$ Aprovado: junho/14 